\title{
Ocular leprosy in Ceylon
}

\author{
LLOYD WEEREKOON \\ Lniversity of Malaya, Kuala Lumpur
}

\section{Historical survey}

Leprosy is an ancient disease, but it is not possible to say with any certainty when and how it was introduced into Ceylon. It may be presumed that the disease came by way of India, the neighbouring sub-continent, by way of the trade routes. The earliest authentic reference to the disease in Ceylon is to be found in the Mahawansa, an ancient Buddhist chronicle, written about the 6th century A.D. Reference here is to a patient suffering from the disease whose mental condition was treated by the Surgeon-King, Buddhadasa (398-426). No mention is made of any treatment of his leprotic condition, but lepers were obviously not segregated for the patient was allowed in the market place and notice was taken of him because of the abusive language he hurled at the king, not because of his disfiguring disease.

The next reference to the disease takes one into the period of the Dutch occupation of the island, when the Dutch governor, Thomas van Rhee (1692-1697), noticed an increase of leprosy amongst the Dutch families in Ceylon, especially among those married to native (mestiche) wives. He attempted to introduce legislation to enforce segregation of the sufferers in some asylum, but the Dutch East India Company recoiled at the cost of such an undertaking and suggested that the governor build an institution out of the charitable funds of the deaconry. These were scarcely sufficient for its own purposes and nothing came of the idea. Van Rhee, as an alternative, issued a plakaat forbidding lepers to show themselves in the streets and requiring them to live outside the town. In the next century, Governor Cornelius Johannes Simon (1 703-1707) was more successful in obtaining the consent of the Company to erect a hospital, and a site was chosen on the Kelani River, at Hendela. The project was completed during the time of the next Governor, Hendrick Becker (1 707-1 736), and there the hospital stands to this day, though nothing remains of the original building save a plaque preserved for posterity and dated i 708. The Governor also issued a proclamation ordering all those infected with the disease to give "information" presumably for registration purposes, and forbidding lepers "to come into the Fort or the Pettah" on pain of a whipping by the Caffirs, a police regiment brought over from Africa. In British times, the Leper Asylum was placed for the first time under a Ceylonese doctor, Joseph Sansoni, who had been trained at Pisa for the purpose. Until then the medical services had come under a military administration. Since Independence in 1948 there has been no great change in the anti-leprosy campaign, though there has been a greater relaxation of surveillance and many non-infective lepers are now placed on parole and are at liberty to leave the precincts of the hospital. Many patients, however, return eventually to the hospital, especially those with mutilating deformities which they feel proclaim their condition rather obviously. Certainly all the eye cases return to the hospital and remain as in-patients. According to the last census, of 4,279 cases of leprosy in the whole island, 
I,944 were infective. 630 of these are at Hendela, the rest being distributed between Mantivu in Batticaloa and other smaller leper colonies in the south. 2,335 cases were noninfective; most of them have returned to their homes, but report regularly at the Colombo clinic for observation and periodic tests. A somewhat disturbing finding has been that the number of fresh cases has shown no appreciable decrease but has remained fairly steady (see Table I).

Table I Leprosy in Ceylon

\begin{tabular}{llr}
\hline No. of cases & $\begin{array}{l}\text { Total } \\
\text { infective } \\
\text { Non- } \\
\text { infective }\end{array}$ & $\begin{array}{r}4,729 \\
\mathrm{I}, 944\end{array}$ \\
2,335 \\
\hline $\begin{array}{l}\text { No. of fresh } \\
\text { cases }\end{array}$ & $\begin{array}{l}1963 / 64 \\
1964 / 65\end{array}$ & 218 \\
& $1665 / 66$ & 174 \\
\hline
\end{tabular}

\section{Ocular involvement}

The eye is never the primary seat of the infection. If and when the eye itself is involved, it is always secondary to some primary lesion elsewhere in the body. Most authorities claim that the eye will eventually be affected in every case. Tamesis (1963), for instance, maintained that the disease in its natural course will eventually invade the eye and cause blindness unless its progress is interrupted by therapy. This, however, is not the universal opinion. Certainly in Ceylon only 297 cases showed eye involvement from amongst the 630 cases of leprosy at the Hendela Hospital, i.e. 47 per cent. (Table II). If the total number of leprosy cases in Ceylon, viz. 4,279 are considered, the figure would be reduced to a mere 8 per cent. These may correctly be considered as the total figures for the whole island as, apart from a negligible number, the vast number of eye cases are to be found as in-patients of the Hendela Hospital, while a few attend the Eye Clinic at the same hospital as out-patients. The incidence of blindness due to leprosy is shown in Table III.

It is useful at this stage to distinguish between true ocular leprosy and mere ocular involvement due to affection of the adjacent structures. The latter occurs fairly frequently, and results from a seventh nerve involvement in the disease process leading tolagophthalmos, exposure keratitis, and loss of the eye. This was seen in forty cases. Some form of tarsorrhaphy is generally required to save the eye and vision. True ocular leprosy, on the other hand, involves a direct infection of one of the ocular tissues by the Mycobacterium leprae. The mechanism of infection is still open to debate, and it is not proposed here to re-open the controversy, though it is necessary to mention the various possibilities. The majority favour the neural route via the fifth cranial nerve, the sensory nerve of the eyeball, but others explain involvement of the deeper tissues like the iris by a Herxheimer type of sensitivity response following an earlier bacterial embolism. This was before the recent electron 6 microscopical studies of the irides of lepromatous patients which have clearly demonstrated the presence of Mycobacterium leprae in the smooth muscle cells of the iris (Hashizume and Shionuma, I965). Others favour a blood-borne infection of the Schwann cell as the most likely route (Weddell and Palmer, 1963). Another possibility is that the eyes become infected directly from adjacent infected areas of the lids and eyebrow's, and also from the nasal mucosa. 
Table II Ocular conditions at Hendela Hospital

\begin{tabular}{|c|c|c|}
\hline \multicolumn{2}{|l|}{ Total cases of leprosy } & \multirow{2}{*}{$\begin{array}{r}630 \\
297 \\
47\end{array}$} \\
\hline $\begin{array}{l}\text { Leprosy cases with eye } \\
\text { complications }\end{array}$ & $\left\{\begin{array}{l}\text { No. } \\
\text { Per cent. }\end{array}\right.$ & \\
\hline \multirow[t]{2}{*}{$\begin{array}{l}\text { Particular eye } \\
\text { ccnditions related to } \\
\text { leprosy }\end{array}$} & $\begin{array}{l}\text { Iritis } \\
\text { Iris nodules } \\
\text { Keratitis: corneal nebulae } \\
\text { Corneal ulcer } \\
\text { Adherent leucoma } \\
\text { Anterior staphyloma } \\
\text { Scleritis, episcleritis, episcleral nodule } \\
\text { Lagophthalmos } \\
\text { Blocked lacrimal sac } \\
\text { Secondary glaucoma }\end{array}$ & $\begin{array}{r}110 \\
1 \\
40 \\
4 \\
8 \\
5 \\
72 \\
40 \\
14 \\
3\end{array}$ \\
\hline & Total & 297 \\
\hline \multirow[t]{2}{*}{$\begin{array}{l}\text { Other eye conditions } \\
\text { probably not related to } \\
\text { leprosy }\end{array}$} & $\begin{array}{l}\text { Cataract } \\
\text { Primary glaucoma } \\
\text { Choroidal sclerosis } \\
\text { Macular changes } \\
\text { Optic atrophy } \\
\text { Blepharitis } \\
\text { Catarrhal conjunctivitis } \\
\text { Pterygium } \\
\text { Cysts of lid } \\
\text { Phthisis bulbi }\end{array}$ & $\begin{array}{r}75 \\
1 \\
10 \\
3 \\
2 \\
4 \\
67 \\
12 \\
18 \\
10\end{array}$ \\
\hline & Total & 202 \\
\hline
\end{tabular}

Table III Incidence of blindness (vision less than $3 / 60$ ) at Hendela Hospital

\begin{tabular}{lllll}
\hline \multirow{2}{*}{ Sex } & \multicolumn{2}{l}{ Blindness } & & \\
\cline { 2 - 4 } & No. of cases & Uniocular & Binocular & $\begin{array}{c}\text { Per cent. of all } \\
\text { leprosy cases }\end{array}$ \\
\hline Male & 70 & 43 & 27 & 11 \\
Female & 16 & 9 & 7 & 2.5 \\
\hline Total & 86 & 52 & 34 & 13.6 \\
\hline
\end{tabular}

\section{Clinical features}

\section{EXTRAOGULAR STRUGTURES}

It is common to find the eyebrows and upper lids involved in a leprotic skin lesion. Areas of infiltration become visible with thickening of the tissues. Nodules varying in size from a pinhead to large masses may be present. When the bacilli invade deeply, the hair follicles become involved and the hairs break off or fall out. They certainly do not grow again, and thick infiltrated eyebrows completely devoid of hairs, the so-called alopoecia of the eyebrows, is a frequent finding. Similarly, the upper lids may show small nodules, though strangely enough these are absent in the skin folds of the upper lids, the so-called "immune areas". Involvement of the ciliary margins is frequently seen, giving a thicker edge to the lid, or more commonly absence of the lashes as the follicles become involved in the disease 
process. These areas of involvement of the eyebrows and lids are probably the result of direct contact infection, or by spread of bacilli via the skin lymphatics from adjacent infecteç skin areas of the forehead and temple, and they constitute true leprotic lesions of the ocular. adnexa (Fig. I).

FIG. I Upper lid nodules

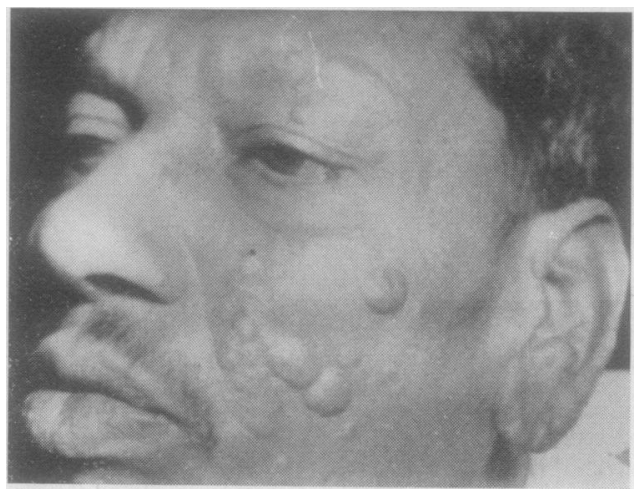

\section{FrG. I Upper lid nodules}

Coming within this category of adnexal lesions would be involvement of the lacrima sac. This could be the result of an ascending infection from the nasal mucosa. On the other hand, it could be secondary to involvement of the nasal bones, i.e. the result of a purely mechanical process. Involvement of the lacrimal gland with a definite leprotico lesion is extremely rare, but it has been described by Cochrane and Sloan (1940). No cases have been observed at the Hendela Hospital.

Seventh nerve involvement by the Mycobacterium leprae leads to facial paralysis affecting the orbicularis muscle of the eye. This leads to inept closure of the lids or lagophthalmos (Fig. 2).

In other cases there is merely an ectropion of the lower lid which may be severe (Fig. 3).

A pure seventh nerve involvement does not give a true leprotic lesion of the eye; it음 merely leads to an ocular complication. It should be noted that the lagophthalmos may appear without the ectropion, and vice versa. The one carries with it the danger of exposure keratitis; the other is merely a disfigurement and a nuisance (epiphora).
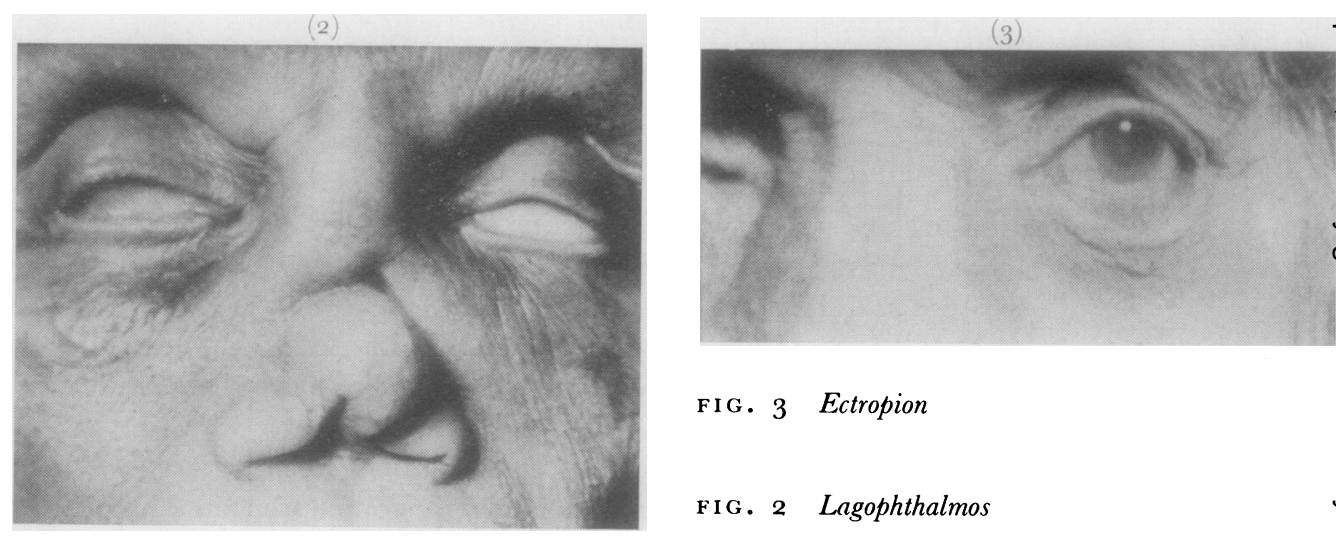

FIG. 3 Ectropion

FIG. 2 Lagophthalmos 
CORNEA

Anaesthesia of the cornea from fifth nerve involvement is not uncommon. This leads to trophic ulceration, but proper care and hygiene of the eyes can do much to prevent inevitable blindness from perforation. Early tarsorrhaphy is indicated in these cases. Keratitis in leprosy may be seen either as an interstitial keratitis, differing from a similar condition found in syphilis in that it is not limited to the upper half of the cornea but eventually affects the whole of it; or one may find, and this is the commoner variety, a diffuse superficial keratitis. This may follow a sclerosing keratitis secondary to a nodular scleritis, or it may follow an interstitial keratitis giving a picture of both deep and superficial keratitis (Figs 4 and 5).

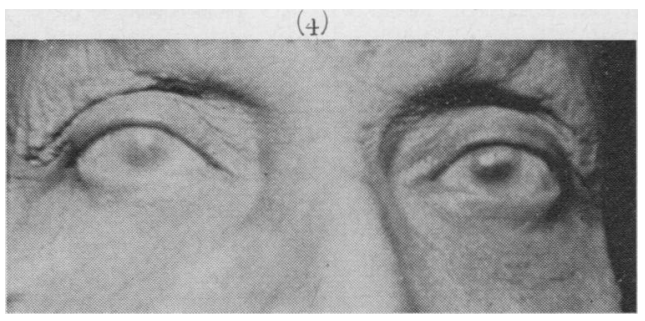

FIG. 4 Interstitial keratitis

FIG. 5 Keratitis with calcification

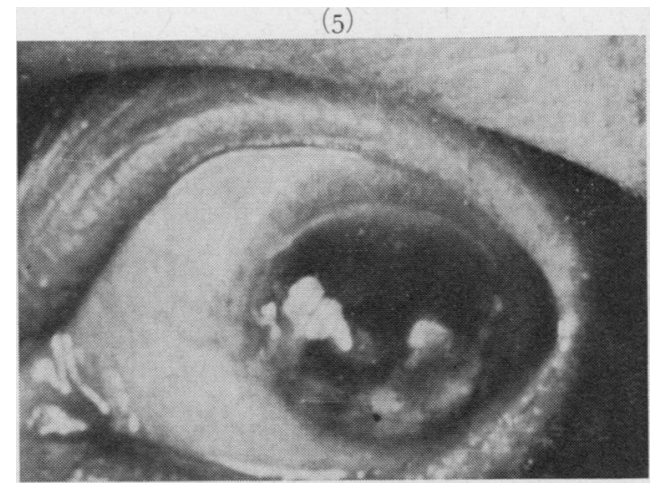

EPISGLERA AND SGLERA

The episcleral nodule rather than the nodular type of episcleritis is the common ocular lesion in leprosy (Figs 6 and 7). A simple episcleritis without nodules is also to be found. This latter is usually evident near the limbus as a triangular leash of vessels. It is evanescent and responds readily to treatment, but the eye is liable to recurrent attacks. The episcleral nodule, on the other hand, begins as an oval, slightly elongated, yellowish-pink mass alongside the lower limbus. It may enlarge gradually until it reaches the size of a small marble. The adjacent cornea is eventually affected with a sclerosing keratitis. It should rightly be referred to as a scleral or episcleral leproma. The so-called "limbal roll" would be formed by these elongated episcleral lepromata lying alongside the lower
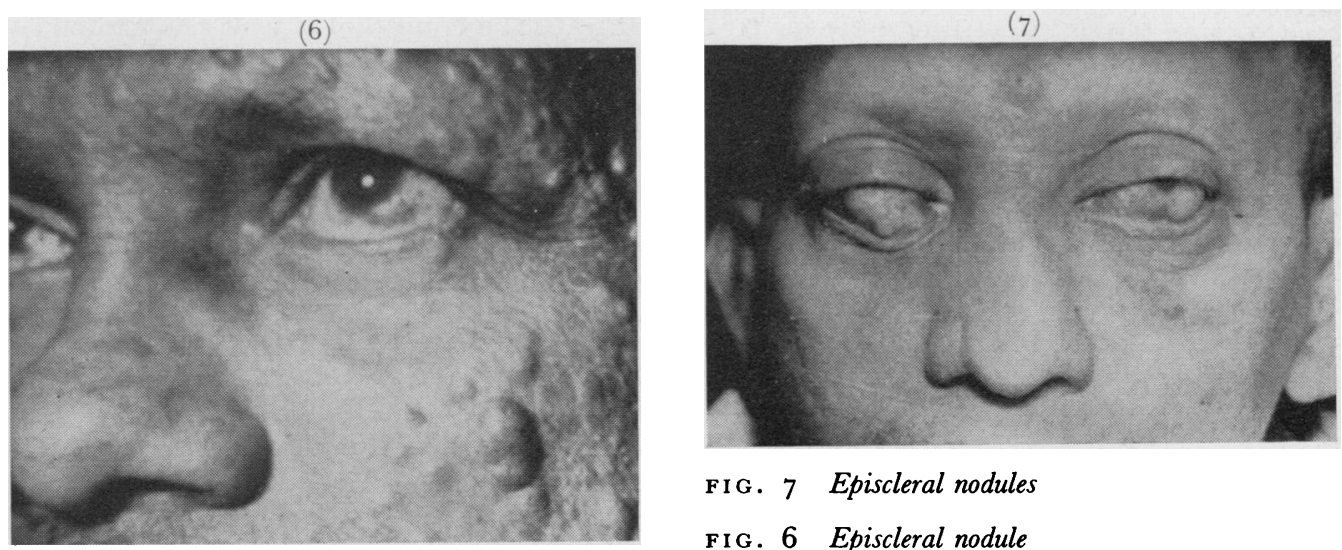

FIG. 7 Episcleral nodules

FIG. 6 Episcleral nodule 
limbus. The episcleral nodule found in non-specific cases is easily distinguished from the्ष्ञ leprotic episcleral nodule. It has a roughened surface, is found only in the 3 or 9 o'clock position, is always an appreciable distance ( $\mathrm{I}$ or $2 \mathrm{~mm}$.) from the limbus, and never en larges to the size reached by the latter. The leprotic nodule, on the other hand, has as smooth shiny surface, and is always to be found alongside and almost touching the lowe limbus.

IRIS AND GILIARY BODY

These two structures bear the brunt of the ocular infection. Involvement may be by on $s$ of four ways:

(a) Miliary lepromata may appear as minute pinpoint to pinhead white spots on the surface of the iris, and not necessarily near the pupillary margin as has been previousl $\frac{0}{6}$. described. They may enlarge to form pearly nodules or, as has been described by othec authorities, they may be nipped off and fall into the anterior chamber where their future is unknown (this has not been observed in our series). When they remain attached to the iris, they infiltrate deeper into the tissues and involve the ciliary body. This was observedg in one of our cases.

(b) Solitary lepromata may appear as large, single, yellowish-pink nodules in and on the surface of the iris near the anterior chamber angle and extending along it (Fig. 8).

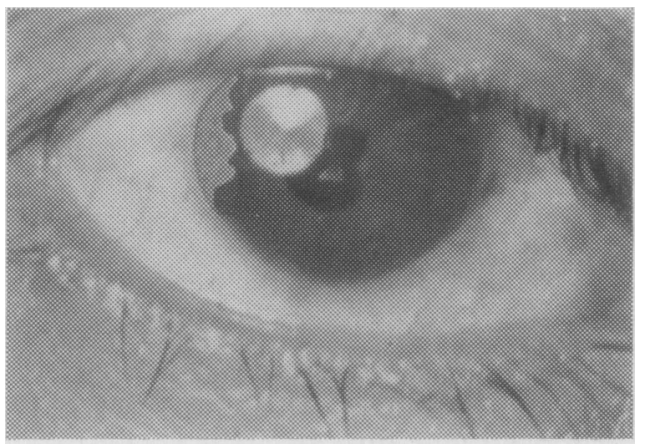

FIG. 8 Iris lepromata filling the anterior chamber angle

(c) Chronic plastic iridocyclitis is unfortunately a very common finding. It is so in sidious that there is no pain, no tearing, and no noticeable redness of the eye, so that the patient does not come for treatment until the condition is well established, with the pupi bound down by adhesions. Keratic precipitates are not a usual feature in these cases as the lesion appears to be more iridic than ciliary. There is no doubt that this insidious iritis iso the cause par excellence of blindness in leprosy. In this series, I 12 cases showed involvement of some part of the uveal tissue.

(d) Acute plastic iridocyclitis is less often seen, and is probably the result of a Herxheimet type of reaction following DDS therapy or as part of an acute "lepra reaction". One such case is reported in this series: a young patient who appeared with an acute plastic iritis in $\stackrel{\infty}{?}$ the right eye. He had pain and a thick exudate in the vitreous, besides a marked flare ando a hypopyon in the anterior chamber. He proffered no history of contact, but during the period of investigation developed a generalized nodular rash which was suspected to be leprosy. This was confirmed by the leprologist who also informed us that he had previously treated the patient. 
POSTERIOR SEGMENT LESIONS

These are extremely rare. Apart from the anterior choroid, the retina and posterior choroid are seldom if ever involved. Somerset and Sen ( 1 956) found only two cases in $25^{6}$ consecutive cases of leprosy routinely examined by them. Choyce (1964) has described a lesion at the periphery of the retina in a case of leprosy, but admitted that it could well be due to some other diseasc such as syphilis or tuberculosis. Recently, Chatterjee and Chaudhury ( 1964 a,b) reported what appeared to be characteristic lesions in four of their series of 250 cases, fifty of which had been examined ophthalmoscopically. In our series, no retinal or choroidal lesions were discovered other than macular and choroidal degenerations which could both have been due to other causes. Most of those who attended the Eye Clinic at the Hendela Hospital for treatment had already had their eyes involved in one way or the other, and, apart from the aphakic eyes, fundus visualization was extremely difficult because of pupillary adhesions. Only a systematic examination of otherwise unaffected eyes in leprosy patients can give any definite information on this point.

GRYSTALLINE LENS

This is probably never directly involved in a leprotic lesion, but could possibly be secondarily affected as an extension from an iritis via pupillary bridges.

OPTIG NERVE

This was not involved in the disease process. Though cases of optic neuritis have been reported, we have had no such cases in our series. Likewise we have had no cases of ocular palsy that could be specifically attributed to the disease.

\section{Treatment}

DRUGS

The drug that has proved most effective in the treatment of the general disease, one of the sulphones, viz. DDS or dapsone, has so far been rather disappointing in treating ocular leprosy. The current impression is that it brings only slight improvement in the eye condition. This is contrary to the observations of Dobrovič and Schaller (1963), who stated that eye changes in leprosy were much more frequently found in patients who had not received any anti-leprosy treatment, and that deterioration in the ocular condition was much greater in these patients. In our patients at Hendela one has had to depend on local treatment with steroids and mydriatics. This last is still the sheet anchor of all ocular treatment in leprosy. The adhesions between iris and lens have to be broken down, and the earlier the mydriatic is employed the better the results. Local steroids are equally necessary to reduce the inflammatory reaction, while systemic steroids such as prednisolone and other anti-inflammatory drugs such as phenylbutazone are used almost routinely.

Reaction in leprosy responds readily to anthiomaline, a trivalent antimony preparation. This is used as frequently as parenteral steroids like hydrocortisone are used intramuscularly. The antimony preparation merely helps to resolve the accompanying iritis; it does not replace local treatment with steroids and mydriatics.

Once posterior synechiae have formed, but before complete occlusion of the pupil, it is necessary to keep the pupil, or what is left of it, mobile. This was done by instilling a strong mydriatic once a week. This treatment may keep the patient from comfortable 
near vision for the first half of the week but certainly prevents further extension of the adhesions.

\section{SURGERY}

This is necessarily plastic and reparative. Tarsorrhaphies for lagophthalmos, and the Kuhnt-Symanowski operation for the ectropion are most commonly employed. The blocked sac, however, is extirpated rather than repaired, for obvious reasons.

Our leprosy patierits have responded to cataract surgery very well, which is contrary tôn the usual teaching. In this series, 25 extractions, intracapsular as well as extracapsular $\vec{b}$ were performed on patients at Hendela, and in only one case was the eye lost after a violent uveal reaction; and this patient had had an iris leproma removed from that eye before the्ल

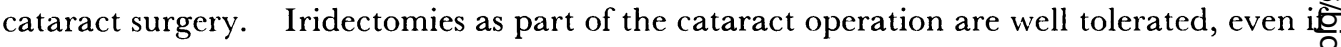
there has been an earlier chronic iritis. Episcleral nodules are best excised before theye infiltrate deeper tissues (sclera and ciliary body), but here too there are obvious reserva $=$ tions, for example a single functioning eye, unless this is done early and under adequat steroid cover.

Keratoplasty has so far been attempted in only one case. The eye responded well to the corneal surgery and the graft was clear on the fourth day, but the patient developed $x$ hyperpyrexia on the fifth day and succumbed to this illness.

\section{Conclusion}

Ophthalmic surgery is reparative rather than amputative in this field, and the aim shoulds be the restoration of vision as well as of a pleasanter physical appearance. The patientso referred to here were all long-standing cases who had not had the benefit of early sulphone्ष्๊ treatment when they first contracted the disease. Some had in fact been resident at the hospital for 30 years, long before the introduction of sulphone therapy at this institution $\frac{0}{3}$

With the earlier detection of cases and their early treatment with sulphones, or with the new anti-leprosy drug, B 663 (not as yet employed at Hendela), it may be expected that the many ocular deformities and complications now seen in leprosy patients may be pre vented. The aim should be to prevent eye complications rather than to make a "last ditch" ? attack on ocular disease after it has set in. It is recommended, therefore, that the eyes of all leprosy patients and not merely of those attending for eye treatment should be examineof monthly. All that is immediately required is a report on the pupil reactions under the stimulus of a bright torch light. Suspicious cases should be referred to the Eye Clinic for more detailed examination under mydriasis. Treatment could then be initiated at $a$ much earlier stage, and many more eyes could be saved. The aim should be to detec ocular complications before the leprosy patient becomes an eye patient, and this can be done only if the leprologist is prepared to share the responsibility of its early detection.

It remains for me to acknowledge my indebtedness to the following officers without whose help this pape would not have been possible:

Mr. Kalinga-Mudali of the Health Department, Ceylon, for the excellent photographs and ocular trans parencies;

Dr. de Alwis and Dr. R. Canagaratnam, successive Medical Officers-in-Charge of the Leprosy Hospital Hendela, for their infinite trouble in providing figures from their hospital records, and facilities for photograph $\Omega$ ing the patients;

Dr. P.J. de Fonseka, Superintendent of the I.eprosy Campaign, for providing the statistics for Ceylon as whole. 


\section{References}

ChATterJeE, S., and chaudhury, D. s. (1964a) Leprosy Rev., 35, 88 - - (1964b) Int. F. Leprosy, 32, 53.

CHOYCE, D. P. (1964) "The eyes in leprosy", in "Leprosy in Theory and Practice", ed. R. G. Cochrane and T. Frank Davey, 2nd ed., chap. 17, pp. 310-321. Wright, Bristol COCHRANe, R. G., and SLOAN, T. B. M. (1940) Leprosy in India, 12, 83 DOBRovič, D., and SCHAller, K. F. (1963) Ethiopian med. J., I, I 47 hashizume, H., and shionuma, e. (1965) Int. F. Leprosy, 33, 6 i SOMERSET, E. J., and SEN, N. R. (1956) Brit. F. Ophthal., 40, I67 tamesis, J. v. (1963) J. Philipp. med. Ass., 39, 107 WEDDELl, G., and PALMER, E. (1963) Leprosy Rev., 34, 57 